\title{
Registro ou obra? O lugar da performance no trabalho de Tony Camargo
}

\section{Registration or art? The place of performance in the work of Tony Camargo}

Yasmin Fabris ${ }^{1}$

Ronaldo de Oliveira Corrêa ${ }^{2}$ 


\section{Resumo}

Neste artigo faremos uma abordagem sobre o lugar da performance no circuito da arte contemporânea. Para isso, realizaremos uma reflexão sobre a obra de Tony Camargo, artista visual e performer que tensiona os limites impostos à arte performática ao capturar e editar as fotografias de suas encenações. Nosso olhar para a série Fotomódulos objetiva a compreensão de como e quando, para o artista, o registro da performance torna-se obra. Para isso, entrevistamos Tony com a intenção de entender quais camadas são sobrepostas à sua atuação performática na produção e pós-produção das fotografias que capturam suas gestualidades. Não temos como pretensão desenvolver uma análise crítica da qualidade formal de seu trabalho, mas sim cartografar os procedimentos que possibilitam, para Tony, que a captura do gesto performático se torne artefato de museu. Articulado à análise, trabalharemos, a partir de Auslander (2013) e Agra (2009), os tensionamentos impostos à documentação da performance, vista por alguns como outra forma de arte.

Palavras-chave: Tony Camargo, arte contemporânea, performance, Fotomódulos, documento.

\section{Abstract}

In this article, we will take an approach on the place of performance in the circuit of contemporary art. To accomplish that, we will reflect on the work of Tony Camargo, visual artist and performer who stresses the limits imposed on performance art by capturing and editing photographs of his plays. When we look at the Fotomódulos series, we try to understand how and when, for him, the performance record becomes a work of art. The artist was interviewed with the intention of understanding which layers are superimposed on his performance in the production and post-production of the photographs that capture his gestures. We do not pretend to develop a critical analysis of the formal quality of his work, but rather to map the procedures that makes possible, for Tony, to capture the performative gesture as a museum artefact. From Auslander (2013) and Agra (2009), we will articulate the tensions imposed on the documentation of the performance, seen by some as another form of art.

Keywords: Tony Camargo, Contemporary Art, Performance, Fotomódulos, Document.

ISSN: 2175-2346

1yasfabriss@gmail.com

2 olive.ronaldo@gmail.com 


\section{Introdução}

A conservação/preservação da arte contemporânea é tema que levanta muitos debates. Por incorporar meios e materiais dos mais diversos, além de tecnologias rapidamente superadas e substâncias perecíveis, a arte contemporânea é um desafio claro para os conservadores e restauradores (KAC, 2015). Neste sentido, o Museu de Arte Contemporânea da Universidade de São Paulo (MAC/USP) realizou em 2014 um seminário a fim de explorar as questões que envolvem a preservação deste tipo de prática artística. O evento, denominado Arte Contemporânea: preservar o quê?, debateu as estratégias de preservação e necessidades específicas de conservação da arte contemporânea.

Conforme explica Carvalho (2015), o processo de conservação e restauração só existe porque as peças sofrem um processo de envelhecimento que, na maior parte das vezes, as deteriora. Esse envelhecimento que promove alterações na matéria que as compõe, de modo geral, são mudanças decorrentes de um processo natural. Aos conservadores e historiadores resta compreender de que modo o tempo atuou na obra, se de maneira positiva - a alteração como pátina - ou negativa - gerando interferência no processo de fruição estética ${ }^{1}$.

As obras que envolvem uma dramatização performática pressionam, então, os processos previstos nas teorias de restauração existentes, que tratam especialmente de objetos físicos. A arte contemporânea acrescenta ao binômio conservação/restauração a questão da imaterialidade da obra. Se compreendermos, assim como proposto por Danto (2006), que a arte contemporânea ganha sua efetividade na individualidade da proposição artística e que a fruição e compreensão da obra está vinculada a um conceitualismo inerente à peça, a questão da conservação torna-se ainda mais complexa. A partir da argumentação de Danto (2006), Carvalho (2015) interpreta que a compreensão do significado pretendido pelo artista na execução de uma obra implica que o processo de intervenção e a ação do tempo não comprometam o significado que a obra adquiriu junto a certo grupo social (CARVALHO, 2015, p.25).

Para sustentar seu argumento sobre essa "preservação do conceito" mesmo em obras 'desmaterializadas', Carvalho (2015) utiliza como exemplo a obra de Robert Smithson². Para o autor, a possibilidade de fruição de obras que não estão disponíveis - devido à sua localização ou efemeridade, por exemplo - se dá pelo acesso a seus índices - fotografias, documentos, vídeos, resíduos -, sendo possível, por meio dessas estratégias de registro, conservar o conceito e o conhecimento do artista. $\mathrm{Na}$

\footnotetext{
1 O dilema entre o tempo bom e tempo ruim é explicitado por Carvalho (2014) com o seguinte exemplo: "se a obra "Você em graduação vertical" da série "Homenagem ao espectador", de Ubi Bava - construída com espelhos convexos sobre uma superfície de acrílico -, for encaminhada para conservação porque um dos espelhos se quebrou ou porque o material metálico que confere o reflexo oxidou, o restaurador, no processo de trabalho, deverá, com o auxílio dos conhecimentos críticos da história da arte, analisar: a) se deve restaurar o espelho, colando as partes; ou b) se deve substituí-lo por outro novo. Qual dessas decisões preservará melhor a intenção do artista? Se a obra for considerada autoral, o tempo bom (a pátina) pode não existir, porque a proposta do artista ao utilizar espelhos para refletir o espectador, homenageando-o, foi comprometida pela oxidação do material metálico ou por um reflexo cheio de defeitos provocados pela colagem do espelho quebrado. Nesse caso, a alternativa a ser considerada é a presença do tempo ruim, isto é, a presença de dano, e a opção pela substituição do espelho é a que melhor preservará a intenção do artista na obra, devolvendo suas qualidades óticas. A reconstrução ou reposição de parte da obra estaria restaurando o significado do objeto, pois, como salienta Jiménez "o significado (...) também é matéria de restauro" (CARVALHO, 2015, p.21).
}

2 A referida obra trata-se da Spiral Jetty, que consiste no deslocamento de grandes quantidades de rocha e terra que se projetam em forma de espiral em um lago salgado. "A desmaterialização do objeto físico, para Smithson, significa que nada é sólido, tudo é permeável" . O local, de difícil acesso, e as condições físicas e dimensionais inviabilizam um tratamento de conservação tradicional (CARVALHO, 2014, p. 26). 
argumentação de Carvalho (2015), mesmo quando a matéria é impossível de ser restituída ao seu estado íntegro, é possível manter seu valor simbólico 3 .

Contudo, vale lembrar que na performance, por vezes, a obra só adquire significado - tanto para o artista, quanto para o grupo social - no momento exato de sua realização. Neste contexto, o debate acerca da restauração, conservação e documentação se intensifica. Para muitos autores a live art acontece no domínio absoluto do "agora", sendo a reprodução ou o registro inalcançável. Sobre este tema, a performer norte-americana Laurie Anderson (apud AGRA, 2009) afirma que a documentação da performance se transforma em outra "forma de arte". Para a artista, a performance "é o braço anárquico e experimental de nossa cultura" (ANDERSON in GOLDBERG, p.6 apud AGRA, 2009, p.247). A fala de Anderson evoca uma posição recorrente acerca da reedição da performance, comumente vista como algo impossível ou evitável (AGRA, 2009). Peggy Phelan (1993), em seu artigo The ontology of performance: representation without reproduction, afirma que:

Performance's only life is in the present. Performance cannot be saved, recorded, documented, or otherwise participate in the circulation of representations: once it does so, it becomes something other than performance (PHELAN, 1993, p. 146). ${ }^{4}$

Na contramão dos que advogam a impossibilidade do registro e documentação da performance, está a produção do artista curitibano Tony Camargo. Na série Fotomódulos e Videomódulos Tony empresta seu corpo e realiza performances que são documentadas por meio de fotografias e vídeos.

Tony Camargo é artista plástico, nasceu em 1979 em Paulo Freitas, interior do Paraná, e mudou-se para Curitiba em 1997 para cursar Artes Visuais na Universidade Federal do Paraná. Ainda na universidade, em 2000, Tony criou junto com outros colegas o coletivo Pipoca Rosa ${ }^{5}$. Em 2002, o artista teve sua primeira exposição individual, a Tento, que ocorreu em Curitiba no Museu Alfredo Andersen (FREITAS, 2011). Hoje ele já soma 17 individuais e mais de 70 participações em mostras coletivas no Brasil e no exterior. Suas obras compõem o acervo de diversos museus de arte contemporânea do país, como o MAM SP (Museu de Arte Moderna de São Paulo), MAC CE (Museu de Arte Contemporânea do Ceará), MAC PR (Museu de Arte Contemporânea do Paraná), MAC RS (Museu de Arte Contemporânea do Rio Grande do Sul), MUSA UFPR (Museu de Arte da UFPR), entre outros.

Apesar de nos atentarmos neste ensaio à uma série específica de sua produção, a obra de Tony é muito mais extensa e diversificada. Seu trabalho contempla outras séries como as planopinturas, as fotoplanopinturas, os videomódulos, além de desenhos e objetos.

Neste artigo temos por objetivo refletir sobre o trabalho fotomódulos de Tony Camargo, buscando compreender como e quando, para ele, o registro da perfor-

30 autor explicita que, no caso de trabalhos em que as experiências estéticas são indiciais, o único elemento que se pode restaurar é o suporte que carrega a obra - imagens, vídeos, documentos - e a proposição da obra.

4 A única vida da performance é no presente. A performance não pode ser armazenada, gravada, documentada, ou, de outro modo, participar da circulação de representações: uma vez feito isso, torna-se outra coisa que não a performance (tradução livre dos autores).

5 Participavam do coletivo, além de Tony Camargo, Lílian Gassen, Lívia Piantavini, Wiliam Machado, Otávio Roesner, Raíza Carvalho (FREITAS, 2011). Como ação inaugural do coletivo, os artistas espalharam dez mil saquinhos de pipoca doce em frente às principais instituições artísticas de Curitiba (FREITAS, 2011). 
mance torna-se obra. Os fotomódulos consistem na captura de um momento performático, por meio da fotografia, e sua passagem para o suporte tridimensional. A obra, enquanto encenação gestual, não existe para fruição estética de espectadores. Desta maneira, um fotomódulo só é apresentado ao público quando a imagem encontra um suporte, um canvas, e a ela são adicionadas novas camadas, com a pós-edição digital e a intervenção pictórica de elementos geométricos na fotografia até a sua saturação ${ }^{6}$.

Entrevistamos, então, Tony Camargo com a intenção de entender quais são essas camadas sobrepostas à sua atuação performática na pós-produção ${ }^{7}$ das imagens e qual o lugar da performance no seu trabalho. Não temos como pretensão realizar uma análise crítica da qualidade formal da sua produção, mas sim cartografar os procedimentos que possibilitam, para Tony, que a captura do gesto performático se torne artefato de museu.

A estratégia metodológica utilizada baseou-se na narrativa do artista como forma de acessar as intencionalidades e os processos que atravessam seu trabalho. Para isso, nos apoiamos na história oral, seguindo as orientações de Thompson (1992), Corrêa (2008) e Costa (2014), por meio da realização de uma entrevista temática semi-estruturada com o artista. A transcrição da entrevista foi feita em turnos, a fim de sistematizar a narrativa para análise do conteúdo das falas ${ }^{8}$. Almejamos reconstruir, a partir da entrevista, a experiência do artista e interpretar os sentidos explicitados em sua narrativa. Articulado à análise, trabalharemos alguns embates que envolvem a documentação e o registro da performance. Destacamos que os trechos das entrevistas que constam neste artigo foram cedidos e tiveram sua divulgação autorizada por Tony Camargo.

\section{Documento e performance}

No que se refere à documentação da arte, em especial na bibliografia que trata da performance, são numerosas as divergências entre autores. A ldeia de documento, por si só, apresenta diversas definições. Rodrigues e Crippa (2015), ao refletirem sobre a preservação da arte contemporânea, compreendem o documento como "todo e qualquer registro feito da obra de arte contemporânea com intencionalidade de registro documental (fotografias, vídeos, projetos, manuais de instrução, etc.)" (RODRIGUES; CRIPPA, 2015, p.2). Os autores argumentam, então, que no caso da performance, o que é guardado num acervo, por exemplo, não é a obra em si, mas o registro ou o roteiro da prática performática. A performance, para estes autores, é tratada

6 A série teve início em 2003, com a obra Grampo. Naquele momento o artista não vislumbrava a pós-produção da imagem e seu enquadramento em um suporte tridimensional. Essa fase foi denominada por Tony como pré-fotomódulos. Assim, foi só a partir do recorte e edição da imagem que, em 2006, se iniciou a série fotomódulos.

7 Utilizamos o termo pós-produção com base na definição de Bourriaud (2009) que o descreve como "os tratamentos dados a um material registrado: a montagem, o acréscimo de outras fontes visuais ou sonoras, as legendas, as vozes off, os efeitos especiais. Como conjunto de atividades ligadas ao mundo dos serviços e da reciclagem, a pós-produção faz parte do setor terciário em oposição ao setor industrial ao agrícola, que lida com a produção das matérias-primas" (BOURRIAUD, 2009, p. 7). O autor dedica-se, especialmente ao cenário - desde os anos 1990 - em que artistas interpretam, reproduzem, reexpõem ou utilizam produtos culturais já disponiveis ou obras realizadas por outros artistas. Essas ações que inserem o trabalhos de outros em suas próprias obras contribuem para abolir distinções tradicionais como produção/consumo, criação/cópia, ready made e originalidade (BOURRIAUD, 2009). No caso do trabalho de Tony Camargo, referimo-nos especialmente à ação de tratamento posterior a um material editado, visto que a edição é executada sobre/no trabalho do próprio artista.

8 Com base na pesquisa de Corrêa, Rial e Queluz (2012). 
como informação/documento justamente pelo seu caráter efêmero, pois, para eles, o que permanece não é a obra em si, mas a documentação do que a compõe.

A questão do que é ou não documento também merece certa atenção. Desde o final do século XIX, a noção de documento aplicava-se exclusivamente a textos e arquivos oficiais. Contudo, esta noção foi alargada pela disciplina da história, principalmente pela Escola dos Anais (CELLARD, 2012). Para a história social "tudo que é vestígio do passado, tudo o que serve de testemunho, é considerado como documento ou fonte" (CELLARD, 2012, p.296). Cellard (2012) explica que essa nova perspectiva sobre o documento possibilita que exista uma multiplicidade de fontes documentais, aplicada nos mais diversos suportes ${ }^{9}$. O caso dos documentos gerados a partir de performance ou de práticas artísticas contemporâneas enquadram-se nesta perspectiva alargada. Assim, o registro de uma prática artística, assim como contém um viés documental, no sentido de preservar o índice da obra, também pode adquirir valor enquanto parte ou rastro da própria obra.

Conforme afirma Freire (2015), curadora do Museu de Arte Contemporânea da Universidade de São Paulo - MAC SP, essa problemática entre o registro e a obra que atravessa a preservação e a memória da arte contemporânea acompanha a trajetória do museu desde seu início. Esse atrito, segundo a curadora, é decorrente de mudanças que aconteceram a partir da segunda metade do século passado, quando as práticas artísticas extrapolaram os "limites materiais e epistemológicos" nos quais os museus estavam acostumados a trabalhar.

As novas obras de vertente conceitualista, segundo Freire (2015), sugerem há várias décadas a revisão das práticas museológicas convencionais. Para a autora, diante destas obras o sentido de "preservar" se amplia, tornando o armazenamento em recintos fechados e protegidos, como as reservas técnicas, insuficientes. Neste cenário, os recursos tecnológicos e a memória digital devem ser ferramentas incorporadas ao processo de preservação (FREIRE, 2015).

Contudo, mesmo quando os instrumentos de preservação são constantemente atualizados, os modos de conservar as obras que envolvem performance ainda causam debates. A própria definição de performar exposta no glossário do livro Arte contemporânea: preservar o quê?, organizado por Cristina Freire, salienta que nas práticas artísticas que envolvem performance o processo artístico é tão relevante quanto o resultado final do trabalho:

[...] trabalhos "performados" incluem não somente dança, música, teatro e arte da performance, mas também obras nas quais o processo é tão importante quanto o produto. Nestas, o uso do questionário determina as instruções que os atores, curadores ou profissionais especializados na montagem e/ou instalação devem

\footnotetext{
9 Sobre a questão do documento histórico, destacamos um trecho do texto de Meneses (1998) que diz: "Para reduzir um complicado problema à sua mínima expressão, no nível empírico pode-se dizer que documento é um suporte de informação. Há, em certas sociedades, como as complexas, uma categoria específica de objetos que são documentos desde nascença, são projetados para registrar informação. No entanto, qualquer objeto pode funcionar como documento e mesmo o documento de nascença pode fornecer informações jamais previstas em sua programação. Se, ao invés de usar uma caneta para escrever, Ihe são colocadas questões sobre o que seus atributos informam relativamente à sua matéria prima e respectivo processamento, à tecnologia e condições sociais de fabricação, forma, função, significação etc. - este objeto utilitário está sendo empregado como documento. (Observe-se, pois, que o documento sempre se define em relação a um terceiro, externo a seu horizonte original). 0 que faz de um objeto documento não é, pois, uma carga latente, definida, de informação que ele encerre, pronta para ser extraída, como suco de limão. 0 documento não tem em si sua própria identidade, provisoriamente indisponível, até que o ósculo metodológico do historiador resgate a Bela Adormecida de seu sono programático. É, pois, a questão do conhecimento que cria o sistema documental. 0 historiador não faz 0 documento falar: é o historiador quem fala e a explicitação de seus critérios e procedimentos é fundamental para definir o alcance da sua fala. Toda operação com documentos, portanto, é de natureza retórica. Não há porque o documento material deva escapar destas trilhas, que caracterizam qualquer pesquisa histórica" (MENESES, 1998, p. 95).
} 
seguir para completar a obra, extrapolando as considerações mais convencionais na performance como elenco, cenário e acessórios (FREIRE, 2015, p.180).

A importância do processo no ato performático faz com que autores e artistas, tais como Peggy Phelan, acreditem na impossibilidade da documentação ou reprodução da performance. Lehmann (2007 apud BEBIANNO, 2010), por exemplo, afirma que o centro da arte performática está na imediatidade da experiência compartilhada por artista e público.

A relação entre evento e registro é um dos maiores focos de estudo e criação no campo da performance nas artes visuais (MORAES, 2015). Segundo Moraes (2015), quando a performance se alicerçou na década de 60 e 70, questionava o sistema de arte justamente por resistir à objetificação. A performance do século XX, neste sentido, contestava o sistema de arte tradicional ao propor o próprio corpo como obra de arte $^{10}$ (FERREIRA, 2011). Para Ferreira (2011) quando o performer transforma a obra efêmera e ação cotidiana em arte, ele opera um tensionamento no sistema mercantil artístico. Pode-se pensar, então, que essa inversão é obtida pela mudança de suporte da obra e pela simultaneidade do efêmero (o tempo da performance) e do permanente (o corpo do performer).

Hoje, embora a performance ainda pressione as relações do mercado de arte, os documentos de ações performática já são comercializados sem maiores constrangimentos (MORAES, 2015). Surgem assim, conforme argumenta Moraes (2015), questionamentos a respeito do registro, que pode tanto ser coadjuvante da ação ao vivo, como adquirir vida própria quando há a interferência posterior do artista ou o cuidado na captura da fotografia. Neste sentido, propomos visitarmos o trabalho Fotomódulos de Tony Camargo. Nesta série, o ato artístico não habita no próprio corpo do performer, mas é recurso para que a obra aconteça em outro suporte, mediada pelo registro fotográfico.

\section{O lugar da performance}

Penso na performance que faço para realizar a foto como tinta, como um processo para confeccionar a pintura e não como performance em si.

Tony Camargo (DEL VECCHIO, 2010 apud FREITAS, 2011, p. 54).

Tomamos conhecimento do trabalho de Tony Camargo em uma disciplina ofertada pelo Programa de Pós-Graduação em Design da Universidade Federal do Paraná sobre as relações entre Design e Arte Contemporânea. O artista, por convite dos(as) professores(as) que ministraram o curso, compareceu à sala e dedicou uma tarde para compartilhar conosco notas sobre sua produção. Nesta ocasião, dentre o panorama apresentado por Tony, que contemplava fases distintas de sua trajetória, nos chamou atenção o modo como ele narrava sobre o lugar da performance em seu trabalho, em especial na série Fotomódulos.

O artista, ao contrário do que estampavam as imagens projetadas na parede da sala de aula, não se reconhecia como um performer. O modo como Tony Camargo narrava sobre seu trabalho contrastava com a maneira como nós entendíamos a per-

10 Ver a obra de Goldberg e Canton (2006) intitulada A arte da performance: do futurismo ao presente. 
formance até então, baseados numa ideia de que o gesto ou a ação eram a obra de arte em si mesma, ou seja, produto final da prática artística. Para Tony, ao invés disso, o ato performático fazia parte do seu processo enquanto pintor. Ele não via no momento do gesto o produto de seu trabalho artístico, mas apenas parte do processo, que tinha como finalidade a captura da ação performática por meio da fotografia. É importante ressaltar que Tony Camargo não realiza performances para o público - as imagens que dão origem aos fotomódulos são feitas sem espectadores, capturadas por ele mesmo com a ajuda de tripé.

Tony, em entrevista concedida a Agnaldo Farias e Cauê Alves em 2010 ${ }^{11}$, cita o performer Sigurdur Gudmundsson ${ }^{12}$ como um dos artistas que serviu de referência para realização de seu trabalho nos fotomódulos. A relação com Gudmundsson pode ser vislumbrada de modo mais explícito na série Pré-fotomódulos, quando o equilíbrio por meio da saturação do suporte ainda não havia sido explorado pelo artista. Tony explica que a ideia de excesso verificada na série Fotomódulos, surgiu apenas depois, no momento do desenvolvimento do trabalho:

Comecei a saturar e compactar o espaço plano ao máximo, mas fazendo ele aguentar, fazendo ele não arrebentar, e evitando ficar compositivo, no mal sentido do termo. E para isso, passando mesmo por muitas matrizes. Eu acho que as pinturas e as fotografias, como estrutura básica, passam principalmente pelo Minimalismo, se a gente for pensar no módulo, por exemplo (FREITAS, 2011, p. 81).

Pretendemos demonstrar neste tópico, por meio da narrativa de Tony Camargo, os procedimentos e estratégias conceituais explicitados na fala do artista que possibilitam a transformação do registro performático em peça de museu. Para isso, optamos pela entrevista narrativa temática como estratégia metodológica para alcançar nossos objetivos. A entrevista foi realizada seguindo um roteiro semi-estruturado com quatro questões que visavam orientar o diálogo. A conversa ocorreu em cerca de uma hora e foi gravada com a anuência do interlocutor.

O encontro com Tony Camargo ocorreu em novembro de 2016, quando nos reunimos em seu ateliê, que se localiza em um bairro residencial de Curitiba. $O$ espaço fica nos fundos da casa do artista, em um galpão de pé direito alto, com mais de três metros de altura. No momento da visita, as paredes brancas do ambiente estavam preenchidas por suas telas e desenhos. Alguns trabalhos encontravam-se empilhados e escorados nas paredes, enquanto outros quase atingiam o teto. Ainda, contornando a sala, estavam mesas, balcões e estantes. No canto, o computador do artista, onde ele faz a pós-produção das imagens. O ambiente estava ocupado pelos materiais utilizados por Tony, como latas de tinta, sprays, pigmentos, rolos de papeis, pincéis, fita adesiva, colas, livros, além de pequenos impressos que continham alguns estudos das obras. Convivendo com os objetos, alguns brinquedos de sua filha, que nos visitou algumas vezes durante a entrevista.

11 Disponível em Freitas (2011).

12 Artista islandês nascido em 1942 e que desde de a década de 1960 expõe seu trabalho em mostras individuais e coletivas no mundo todo. 

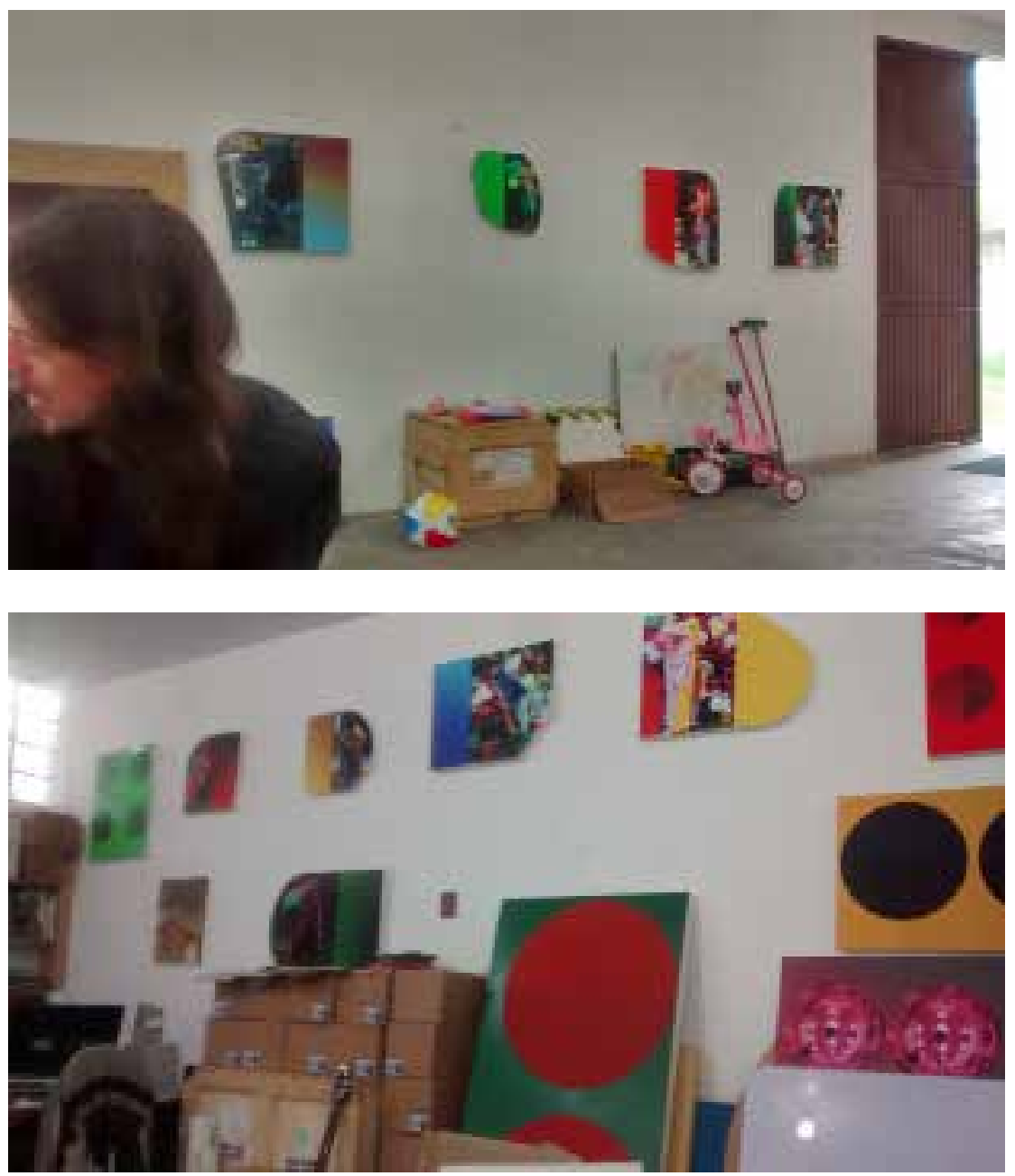

Fig. 1 - Ateliê de Tony Camargo.

Fonte: dos autores.

Antes de nos encontrarmos pessoalmente, já havíamos adiantado ao artista que nossa conversa teria como tema os fotomódulos. Assim, Tony, antes de nos receber, gentilmente pendurou nas paredes alguns exemplares da série para facilitar nosso diálogo. Decidimos por iniciar o roteiro com uma pergunta simples, que nos ajudasse a compreender o lugar da performance em sua produção: Tony, como nasce um fotomódulo?

Ao contrário do que esperávamos, o artista descreveu, desde o início, como surgiu a ideia da série Fotomódulos, assunto que, apesar de não ser nosso interesse principal, acabou por levá-lo a discorrer sobre como entendia a performance em sua produção. Conversando com Tony Camargo, percebemos que três elementos eram essenciais na sua obra: a ideia, a concepção e a presença física. Assim, para ele, apenas a captura do gesto performático, ou seja, o registro, não é capaz de transformar-se em obra, pois exclui o terceiro elemento - a presença. A ausência da densidade física no produto final artístico incomoda Tony e impede a transposição do seu trabalho para um espaço como o museu.

No início - em meados de 2003 -, conforme conta o artista, ele realizava fotografias de gestos performáticos. Mas essas, para ele, ainda não tinham "um lugar no mundo", tratavam-se apenas de imagens avulsas. Tony afirmou durante a entrevista que aquelas fotografias não tinham um porquê de serem apresentadas em um espa- 


\section{ço museológico, visto que podiam ser acessadas da mesma maneira em um livro ou na tela de um computador ${ }^{13}$.}

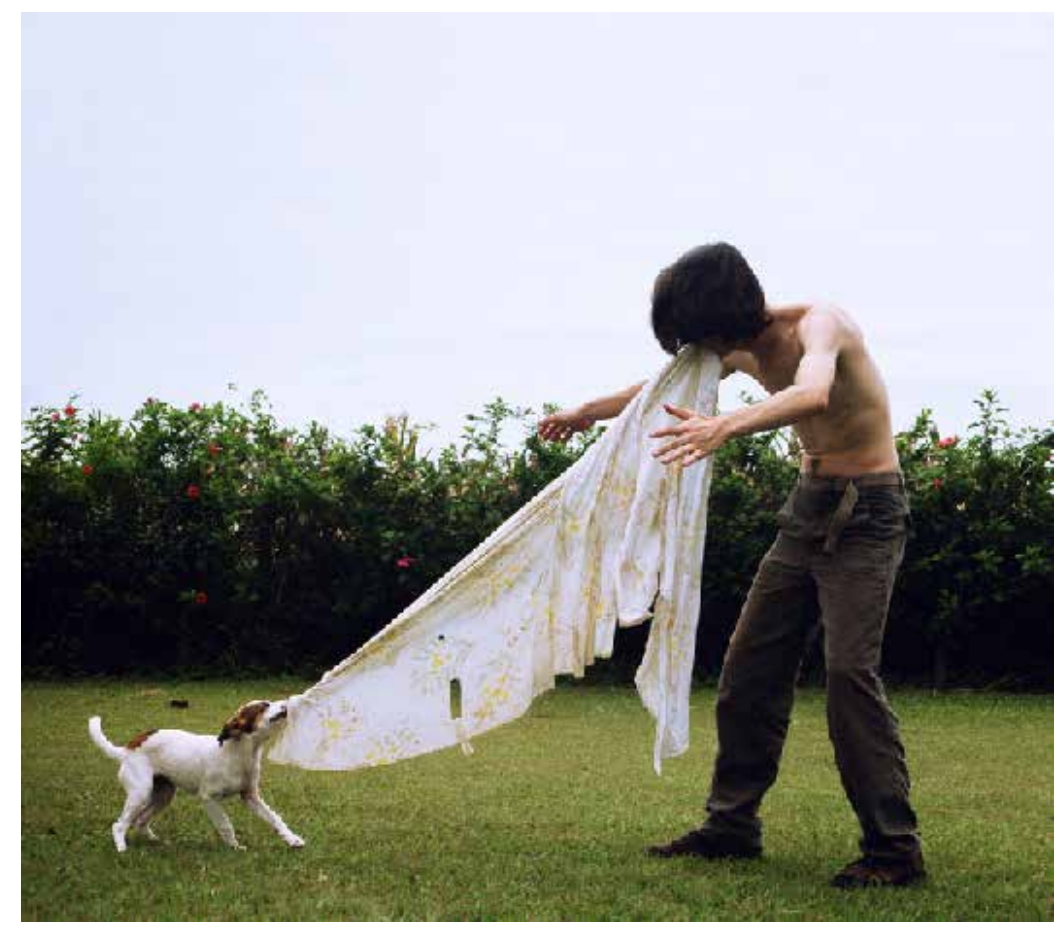

Fig. 2 - Grampo, de 2003 - fotografia em metacrilato. Fonte: Tony Camargo, 2017.

Segundo o artista, foi em 2005 que o modo como ele apresentava as fotografias dos atos performáticos começou a mudar:

[...] Enfim tinha um trabalho que resolvia a questão das fotos que eu estava fazendo. Tudo resolvido num trabalho. Para mim este trabalho solucionava porque tudo nele estava justificado. Tudo que existia nele estava justificado com relação a ideia, a concepção e a presença física. Nada era à toa. Então uma pessoa ir lá e ver ao vivo, sentir a carga desse material usado, sentia a presença do material era fundamental. Tanto que cheguei a pintar na parede para ficar claro isso: esteve aqui a fabricação da coisa (CAMARGO, 2016).

[Entrevista concedida em novembro de 2016]

13 Este trecho da fala de Tony Camargo permite-nos refletir sobre a importância do espaço legitimador no contexto da arte contemporânea. Mesmo nas ações que buscam romper com as estruturas hegemônicas - como é o caso das ações performáticas - existe a preocupação em formatar essas obras para os espaços museológicos. Este dilema está apresentado na obra de García Canclini (2016). 


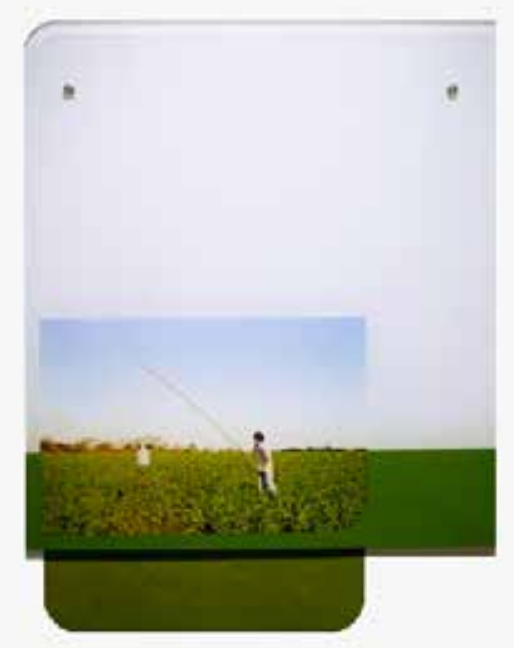

Fig. 3 - Aparelho para apresentação de postura, de 2005/2006 - tinta sintética sobre fotografia em metacrilato, aço e pintura sobre parede. Fonte: Tony Camargo, 2017.

Tony refere-se no fragmento da entrevista à obra Aparelho para Apresentação de Postura (figura 3). A presença efetiva do artefato no mundo implicava, para o artista, um acréscimo no volume do objeto, obtido por meio da colagem de um acrílico grosso à superfície da fotografia. Ainda, parte da obra consistia na pintura de um módulo de cor verde na parede do museu/galeria que apresentava a peça. $O$ deslocamento do público para ver o Aparelho "ao vivo", então, se justificava pela possibilidade do espectador poder sentir, na presença, a "carga" do material enquadrado. O Aparelho, conforme afirmou o artista ${ }^{14}$, acrescentava volume e condicionava fotográfica de modo que ela não podia mais ser concebida de outra maneira, senão como objeto. Assim, a obra quando vista no museu ganhava sentido físico, de modo a não permitir a reprodução em qualquer outro suporte. A fotografia, que antes era imagem permissível de reprodução, com o enquadramento no Aparelho, tornava-se obra, objeto único.

Embora o Aparelho representasse o início da resolução do problema que envolvia as imagens performáticas, que antes "não tinham lugar no mundo", o projeto com as fotografias ainda não estava completamente resolvido para o artista.

[...] O vermelho tinha uma coisa da performance [o artista refere-se a obra representada na figura 4 deste artigo]. Ali no mostarda parece que eu já estou tentando fugir. Tentava escapar dessa coisa da narrativa, ou da imagem da performance. Mas naquele vermelho ainda tinha muito a ver com performance, com postura. $\mathrm{E}$ estava conjugando essa coisa do módulo de cor. Eu estava interessado em coisas opostas mesmo, assim como me interessava a performance e coisas orgânicas, situações orgânicas, etéreas. Também me interessava muito o minimalismo, a existência e autonomia dos objetos no mundo. Até que ponto um quadro cria presença dentro de um ambiente ou não. E são mundos absolutamente distintos. Essa coisa do minimalismo, do módulo, é quase como se fosse o inverso do que existe nesse mundo da imagem (CAMARGO, 2016).

[Entrevista concedida em novembro de 2016]

14 Essa afirmação foi feita em entrevista disponivel em Freitas (2011). 


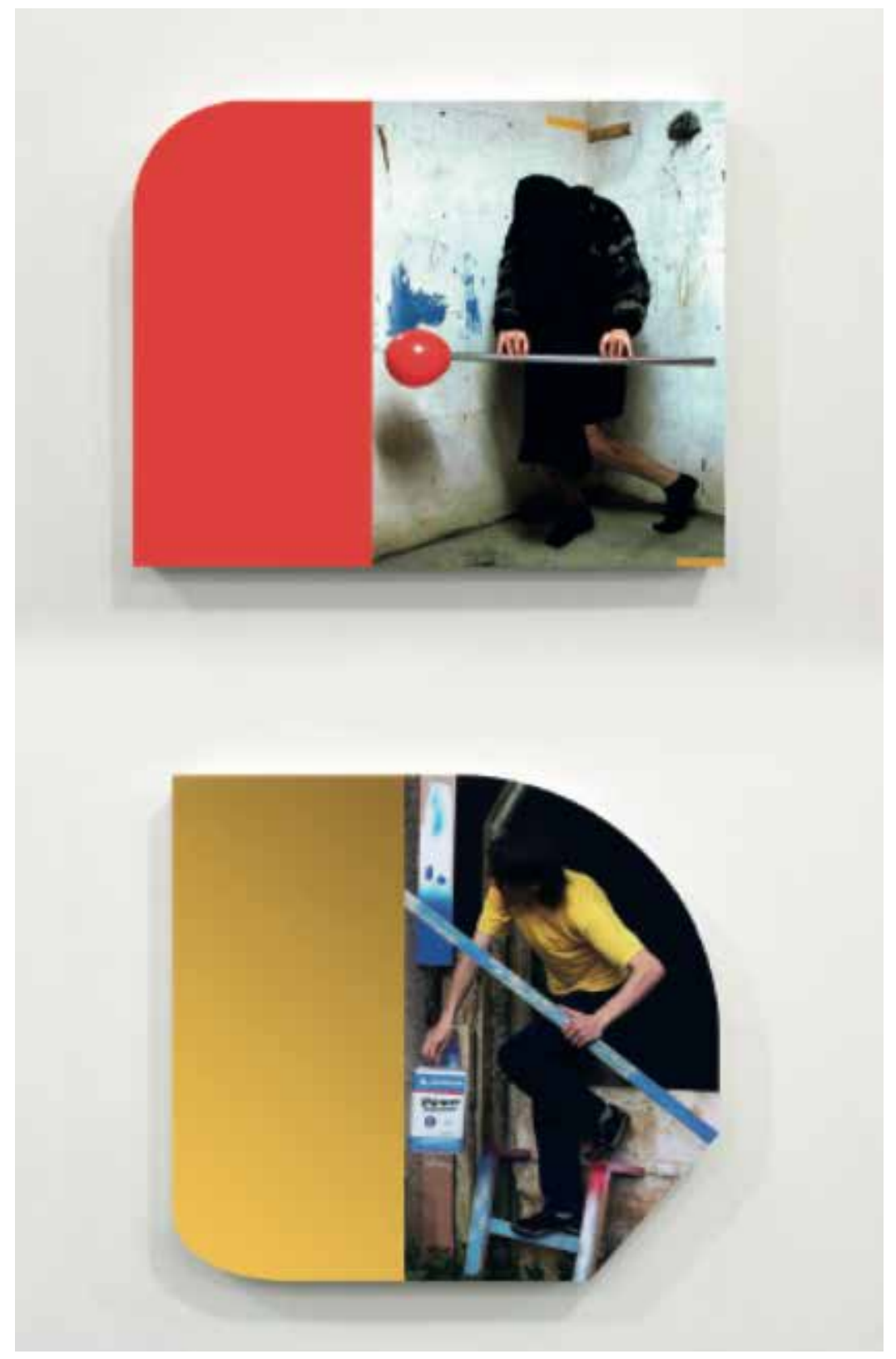

Fig. 4 - Fotomódulos. Acima, obra realizada em 2007, abaixo, obra realizada em 2008. Fonte: Tony Camargo, 2017.

Tony descreve em sua narrativa dois momentos que separam a série Fotomódulos. No primeiro, o ato performático ainda existia como postura, como algo que poderia ser visto, revisitado na imagem. Ou seja, uma cena que explicitava uma ação que acontecera, uma ação passível de narratividade, como o que é visto na obra Grampo de 2003, por exemplo. No segundo momento relatado por Tony, seu trabalho com a imagem volta-se ao corpo. A performance, então, de acordo com o artista, torna-se material para a composição plástica, despida ao máximo de caráter narrativo. Na fala de Tony, é possível perceber que os fotomódulos surgem quando há o trabalho com os módulos de cor, com o recorte da imagem e, posteriormente, com o esvaziamento da narrativa da imagem fotográfica. 
[...] Quando você vê uma fotografia e entende o que está acontecendo, compreende a situação, a narrativa, automaticamente tudo que tá em volta torna-se uma moldura daquilo. E eu queria que isto tivesse muito próximo as coisas que estão do lado. Para isso eu necessitei ir abstraindo a narrativa, e abstraindo (...) Rapidamente cheguei ao ponto de que eu queria: a neutralização completa dessa narrativa. Eu queria que a imagem não tivesse nenhum sentido narrativo que pudesse ser descoberto (CAMARGO, 2016).

[Entrevista concedida em novembro de 2016]

Portanto, para o artista, a imagem enquanto narrativa contaminava a obra, pois capturava a atenção do módulo de cor e levava o espectador a idealizar a performance. A mesma explicação é dada para justificar o encobrimento da face do performer em toda a série. Tony explica que o rosto atrai o olhar do espectador, impossibilitando, assim, que a obra aconteça como um todo. Deste modo, o corpo, para Tony, nada mais é do que um volume na composição visual da fotografia.

Eu encontrei a maneira exata do que eu precisava fazer, que são esses paralelismos da imagem em relação ao objeto. Toda vez que eu faço um trabalho desses é feito um ensaio fotográfico, daí eu seleciono uma imagem que pode ser trabalhada, que funciona bem, e o objeto é recortado. Existe um recorte nessa imagem que origina o formato do quadro, entende como? Você vê que eu tenho uma corcunda que me ajuda sempre. Como tem lá na foto do cachorro lá. Se eu tivesse esperto na época já tinha cortado lá em cima. (CAMARGO, 2016)

[Entrevista concedida em novembro de 2016]

Ao narrar sobre a série e sobre os procedimentos que envolvem a criação de um fotomódulo, Tony destaca que a performance é uma das etapas envolvidas numa reflexão artística visual e objetual. Para ele, a performance enquanto prática efêmera, temporal, que questiona a ausência do suporte, não é relevante, pois é justamente no encontro do objeto tridimensional, no aparelho, que sua obra acontece.

A questão da pós-produção no processo artístico de Tony é tão importante quanto a ação performática que possibilita a captura das imagens. $O$ artista não explicita hierarquias entre os processos envolvidos para produção da obra: a dramatização, a fotografia, a seleção, a edição virtual da imagem, a montagem do chassi e a pintura são parte do que, no fim, quando enquadrado, torna-se um fotomódulo. Tony não hesita ao ser questionado durante entrevista em que momento nasce um fotomódulo: para ele, um fotomódulo "só é quando está pronto. Só quando o quadro está pronto" (CAMARGO, 2016). Enquanto gesto - performance - ou enquanto imagem - fotografia - ainda é matéria-prima para a execução obra.

[...] Então já surgiu, quando de fato surgiu a série, os fotomódulos, ele já surge como aparelho. Que é como eu gosto de ver tudo que eu faço. Aparelho. Aparelho funcional, que tem função. Funciona pra determinada coisa. Então isso é objetual, é plástico. Eu sou um artista plástico. É artes visuais mas é plástico, assim. Sempre é palpável o que eu faço. Embora eu trabalhe com vídeo agora e goste da ideia de imagem, tenha feito trabalhos como aquele livrinho que eu mostrei pra vocês lá, que são trabalhos iconográficos, coisas assim (...) Mas é objetual, sempre existe um objeto assim [...] A performance neste caso ela não existe. Se for ver a rigor assim. Porque ela é parte do processo. Então ela só existe na medida do próprio termo, independente da arte. Aí sim. Pra você desempenhar uma 


\begin{abstract}
determinada coisa há uma performance. Então a performance neste trabalho ela pode até ser elogiada, uma vez que depende quase de uma dança, de uma ação ali. Essa performance, essa forma como o modelo, o personagem está ali, existe. Mas não como performance arte. Não. Como linguagem de performance dentro da arte, não. Porque (...) Tá muito próximo. Para quem vê ao vivo um ensaio vai dizer "Puxa, isso é performance". Mas acontece que eu preciso dessa ação, eu preciso desse momento para criar a minha imagem. Eu estou sempre pensando na imagem, eu não me importo com a performance, com a presença real, ao vivo das coisas (CAMARGO, 2016).
\end{abstract}

[Entrevista concedida em novembro de 2016]

Arthur Freitas (2011) afirma, ao analisar a produção de Tony Camargo, que ele "faz das fotografias matéria-prima para o exercício do pintor, ainda que em sentido amplo" (FREITAS, 2011, p.54). A performance, para Tony, é objeto, é matéria plástica e tridimensional. Para o artista, quando não há volume, as coisas não estão no mundo, por isso, o gesto só se torna arte no momento que há presença - não temporal, mas física.

Sendo assim, o lugar da performance no trabalho de Tony Camargo, como ele mesmo afirma, é "tinta". A performance, conforme argumenta Moraes (2015), integra um pensamento maior, derivado da expansão do pensamento pictórico, do vídeo, da fotografia e do desenho. Deste modo, pode-se pensar que a série Fotomódulos se constitui justamente no tensionamento entre o registo e a obra, pois o último, enquanto objeto real, não existe sem a ação capturada. Para o nascimento de um fotomódulo, o artista precisa sobrepor outras camadas, como a cor, o enquadramento, e adensar a materialidade da fotografia por meio de um canvas real, impresso. A interferência posterior de Tony, tanto na pós-produção da imagem, quanto na montagem do aparelho, faz com que um fotomódulo ganhe lugar no mundo.

\title{
4. Considerações finais
}

Os fotomódulos de Tony Camargo, além de permitirem a discussão acerca da documentação da performance, possibilitam a reflexão sobre a resistência da materialidade, mesmo no contexto da arte contemporânea. A dissolução do artefato, proposta na década de 1960, que tinha como finalidade tensionar o mercado artístico e derrubar as fronteiras do campo, foi driblada por esse mesmo mercado que consegue elevar outras coisas - além da obra - à categoria arte. Os documentos, vídeos, fotografias e rastros do gesto servem como testemunho de um evento vivido, sendo passível, então, de carregar distinção simbólica ou rendimento monetário àqueles que participam do sistema de circulação e consumo desses objetos.

Questionar o lugar da performance, por fim, leva-nos a refletir acerca da argumentação proposta por García Canclini (2016), quando o autor revisita os momentos desconstrutores - desde Duchamp até o século XX - em que a fronteira entre artistas e pessoas comuns se tornou vulnerável, e se estendeu a noção de arte a qualquer objeto. Para o autor, a introdução de artefatos ou ações "ignóbeis" nos espaços artísticos acabou por reforçar a singularidade desses espaços. Assim, o desejo de transgredir essas estruturas que oprimem o campo da arte, do mesmo modo que constrangem - como é o caso da performance - implicam no cultivo dessas mesmas estruturas e narrativas que as justificam. Sendo assim, entendemos que a impossibilidade do re- 
gistro e a efemeridade do gesto, ao mesmo tempo que deseja romper com a ordem vigente, movimenta um mercado que se alimenta da transgressão artística.

O trabalho de Tony Camargo na série Fotomódulos demonstra que o registro e a objetificação do gesto - tanto na fotografia quanto no aparelho - possibilitam que a performance seja interpretada como etapa do processo artístico, e não apenas como exclusividade da ação imediata, que trata do domínio aqui/agora. O encontro entre público e artista é adiado para que o contato ocorra mediado por um suporte editado que sustenta, além do gesto, desenho, geometrias e apagamentos. Cabe, então, aos(às) historiadores(as) e críticos tentar identificar os lugares possíveis da performance no contexto da arte contemporânea. Para Tony isso parece ser um dilema resolvido: sua gestualidade é tinta esperando ser enquadrada.

\section{Referências}

AGRA, Lúcio. "Autor/autores - performance no coletivo" ou de como a reencenação da performance é um fator estratégico para sua pedagogia. Sala Preta (USP), v. 1, p. 247-252, 2009. Disponível em: http://www.revistas.usp.br/salapreta/article/ view/57374/60356 Acesso em: 15 de fevereiro de 2018.

AUSLANDER, Philip. A performatividade da documentação de performance. eRevista Performatus, Inhumas, ano 2, n. 7, nov. 2013.

BEBIANNO, C. A performance e eu, trajetória de uma relação. 2010. Disponível em: http://performanceereenactment.blogspot.com.br/2010/06/performance-e-eu-celina-bebianno.html. Acesso em: 15 novembro de 2016.

BOURRIAUD, Nicolas. Pós-produção. Como a arte reprograma o mundo contemporâneo. São Paulo: Martins Fontes, 2009.

CAMARGO,Tony. Tony Camargo. Disponível em: http://www.tonycamargo.net/index. php?option=com_content\&view=article\&id=7\&ltemid=1. Acesso em: 14 novembro de 2017.

CAMARGO, Tony. Entrevista concedida. Novembro de 2016.

CARVALHO, Humberto. Farias de. Uma metodologia de conservação e restauro para a arte contemporânea. In: FREIRA, Cristina (Org). Arte contemporânea: preservar o quê? São Paulo: Museu de Arte Contemporânea da Universidade de São Paulo, 2015. p. 17-31.

CELLARD, André. A análise documental. In: POUPART, J; DESLAURIERS, J. P.; GROULX, L. H.; LAPERRIÈRE, A.; MAYER, R.; PIRES A Pesquisa Qualitativa: enfoques epistemológicos e metodológicos. Petrópolis: Vozes, 2012.

CORREAA. Ronaldo de Oliveira. Narrativas sobre o processo de modernizar-se: uma 
investigação sobre a economia política e simbólica do artesanato recente em Florianópolis, Santa Catarina, BR. 2008. 305 p. Tese (Doutorado Ciências Humanas) - Programa do Doutorado Interdisciplinar em Ciências Humanas, Universidade Federal de Santa Catarina, Florianópolis, 2008.

CORREAA, R. O.; RIAL, C. S. M. ; QUELUZ, G. L. . "A finalidade é a gente trabalhar aqui mesmo no ateliê [...]" Processos de refuncionalização dos ateliês de artesãos(ãs) no circuito econômico e cultural de Florianópolis, SC.. In: RIAL, C; SILVA, S. R.; SOUZA, A. M.. (Org.). Consumo e Cultura Material: perspectivas etnográficas. 1ed.Florianóplis: Editora da UFSC, 2012, v. 1 , p. 49-74.

COSTA, C. B. A escuta do outro: dilemas da interpretação. Revista de Historia Oral, v.17, p. 47-65, 2014.

DANTO, Arthur. Após o fim da arte: a arte contemporânea e os limites da história. São Paulo: Odysseus, 2006.

FERREIRA, Larissa. Performance tática: cartografia dos desvios. VIS Revista do Programa de Pós-Graduação em Arte da UnB. V.10, n.1, p 112-121, Brasília: 2011.

FREIRE, Cristina. Preservar o futuro? In: FREIRE, Cristina (Org). Arte contemporânea: preservar o quê? São Paulo: Museu de Arte Contemporânea da Universidade de São Paulo, 2015. p. 9-17.

FREITAS, Artur. Tony Camargo: a dialética dos contrários. 1. ed. São Paulo: Berlendis \& Vertecchia, 2011.

GARCÍA CANCLINI, Néstor. A sociedade sem relato. Antropologia e estética da iminência. São Paulo: Edusp, 2016.

GOLDBERG, Roselee; CANTON, Katia. A arte da performance: do futurismo ao presente. Martins Fontes, 2006.

KAC, Eduardo. Prefácio. In: FREIRE, Cristina (Org). Arte contemporânea: preservar o quê? São Paulo: Museu de Arte Contemporânea da Universidade de São Paulo, 2015. p. 7-9.

MENESES, Ulpiano T. B. de. Memória e cultura material: documentos pessoais no espaço público. Revista Estudos Históricos, v. 11, n.21, p. 89-104, 1998.

MORAES, J. M. R. Especificidades do ensino da performance nas artes visuais. DAPesquisa, v.10, n.14, p 24-37, Florianópolis, 2015.

PHELAN, Peggy. "The ontology of performance: representation without reproduction" In: Unmarked: The Politics of Performance, Routledge: London and New York, 1993. 
RODRIGUES, Bruno Cesar ; CRIPPA, G. Arte Contemporânea: o quê e como organizar e preservar? Informação, Memória e Patrimônio: do documento às redes. v. 1. p. 1-18, João Pessoa: ENANCIB, 2015.

THOMPSON, Paul. A Voz do Passado: História Oral. Rio de Janeiro: Paz e Terra, 1992. 